\title{
Oosit In Vitro Maturasyonunda Fosfatidilinositol 4,5- Bifosfat (PIP2) Kullanımının Etkisi
}

\author{
The Effect of Phosphatidylinositol 4,5-Biphosphate (PIP2) \\ on In Vitro Maturation Process of Oocytes \\ Filiz Tepeköy
}

Altınbaş Üniversitesi, Tip Fakültesi, Histoloji ve Embriyoloji Anabilim Dalı

Yazışma Adresi / Correspondence:

Filiz Tepeköy

Altınbaş Üniversitesi, Tip Fakültesi, Histoloji ve Embriyoloji Anabilim Dalı, İstanbul T: +9021270945 28 / $5215 \quad$ E-mail : filiztepekoy@gmail.com

Geliș Tarihi / Received : 27.04.2020 Kabul Tarihi / Accepted : 03.09.2020 Orcid :

Filiz Tepeköy https://orcid.org/ 0000-0003-1901-3787

( Sakarya Tip Dergisi / Sakarya Med J 2020, 10(3):474-483 ) DOI: 10.31832/smj.728050

\footnotetext{
$\ddot{\mathrm{O} z}$

Amaç Hücresel protein dengesi üzerinde etkili olduğu bilinen fosfatidilinositol 4,5- bifosfat (PIP2)'nin, 8-13 yas aralığındaki sı̆̆ır oositlerinin in vitro maturasyon (IVM) sistemine farklı konsantrasyonlarda eklenmesinin, farklı IVM sürelerinde oosit canlılığı ve olgunlașması üzerindeki etkisinin belirlenmesi amaçlanmıștır.

Gereç ve Mezbahada kesimi gerçekleșen sığılardan elde edilen ovaryumlardan aspire edilen kumulus oosit komplekslerinden kumulus hücrelerinin mekanik olarak Yöntemler uzaklaştırılmasıyla soyulan oositler IVM medyumu içerisine alınarak 6 saat ve 24 saat süreyle kültüre edilmiştir. IVM medyumu içerisine $0,1 \mu \mathrm{M}(\mathrm{P} 1), 0,5 \mu \mathrm{M}(\mathrm{P} 2), 1$ $\mu \mathrm{M}$ (P3) ve $5 \mu \mathrm{M}(\mathrm{P} 4)$ konsantrasyonlarda PIP2 eklenmiștir. Kültür sürecinin sonunda tüm gruplardaki 1. mayoz bölünmeyi tamamlayabilen olgunlașmıs oositlerin, olgunlașmamıs ancak canllı̆̆ğını korumuș oositlerin ve ölü oositlerin oranları belirlenmiștir.

Bulgular 6 saatlik IVM sonrasında en yüksek olgunlașma oranının P1 grubunda olduğu, ölü oosit oranının ise P4 grubunda en yüksek olduğu belirlenmiștir. 24 saatlik IVM sonrasında da en yüksek olgunlaşma oranı P1 grubunda görülmüss, P4 grubunda ölü oosit oranının en fazla, P1 grubunda ise en düșük düzeyde olduğu saptanmıştır.

Sonuç PIP2'nin düşük konsantrasyonlarda IVM medyumuna eklenmesi oosit olgunlaşma ve sağ kalım oranlarını artırmaktadır.

Anahtar oosit; oosit toplama; in vitro oosit olgunlaştırma teknikleri; fosfatidilinositol 4,5-bifosfat Kelimeler

Abstract

Objective The aim of the current study was to determine the effects of addition of different concentrations of phosphatidylinositol 4,5-biphosphate (PIP2), which is known to effect cellular protein balance, into the in vitro maturation (IVM) system of bovine oocytes between the ages of 8-13, in terms of oocyte viability and maturation rates at different times of IVM.

Materials Ovaries were harvested from the bovine that were sacrificed in a slaughterhouse. The cumulus oocyte complexes were aspirated from the ovaries and oocytes were denuded by mechanical

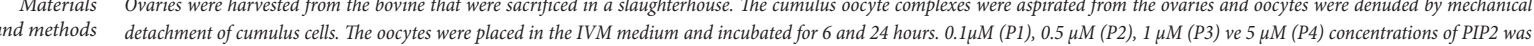
added to the IVM medium. At the end of the culture period, rates of the matured oocytes that were able to complete the first meiotic division, the immature but viable oocytes and dead oocytes were determined in each group.

Results After 6 hours of IVM, the highest maturation rate was seen in P1 group and the rate of dead oocytes was the highest in P4 group. After 24 hours of IVM, the highest maturation rate was also seen in P1 group and the rate of dead oocytes was determined to be the highest in P4 and lowest in P1 groups.

Conclusion The addition of PIP2 at low concentrations to the IVM medium, increases the maturation and viability rates of the oocytes.

Keywords oocytes; oocyte collection; in vitro oocyte maturation techniques; phosphatidylinositol 4,5-biphosphate
} 


\section{GİRIS}

Oosit maturasyonu (olgunlaşması), I. mayoz bölünmenin profaz aşamasının diploten evresinde bekleyen, germinal vezikül (GV) oosit olarak adlandırılan oositlerin, germinal vezikül yıkımının ardından I. mayoz bölünmeyi tamamlayarak II. mayoz bölünmenin metafaz aşamasına (MII) kadar ilerlediği süreci kapsar. ${ }^{1}$ İnfertilite tedavisinde uygulanan yardımcı üreme teknolojilerinden (YÜT) biri olan in vitro maturasyon (IVM), GV aşamadaki olgunlaşmamış oositlerin uygun kültür koşullarında MII aşamaya kadar olgunlaştırılması ve fertilizasyona hazır hale getirilmesidir. IVM, folikül aktivasyonu ve ovulasyon indüksiyonu sonrasında çok az oosit elde edilebilen hastalar için iyi bir seçenektir. Ayrıca, IVM yöntemi sırasında, hastaya hormon indüksiyonu yapılmadığından, hormon tedavisine hassasiyet gösteren polikistik over sendromu (POS) ve ovaryan hiperstimulasyon sendromu (OHSS) olan hastalarda kullanılmaktadır. ${ }^{2}$ IVM yöntemi infertil popülasyonun potansiyelini yaş ve cinsel olgunluktan bağımsız olarak geliştirebilir. ${ }^{3}$ Bu nedenle IVM, kültür koşullarının daha kaliteli oosit geliştirmek üzere optimize edilmesi ile döllenme ve embriyonik gelişim potansiyeli yüksek oositlerin gelişimi için ideal bir yöntemdir.

YÜT uygulamaları sırasında elde edilen oositlerden yaklaşık \%15'inin olgunlaşmamış olduğu belirlenmiştir. ${ }^{4}$ IVM ile elde edilen oositlerin olgunlaşma oranı, doğal siklus ile elde edilenlere göre oldukça düşüktür. Bunun nedeninin IVM protokollerinin en uygun şekilde gerçekleşmemiş olması veya toplanan oositlerin içsel etkenlerinin olgunlaşma için yetersiz kalması olduğu düşünülmektedir. ${ }^{5}$ Mevcut protokoller ile oldukça düşük olan IVM oranları, maternal yaşın ilerlemesi ile birlikte belirgin bir şekilde azalmaktadır. ${ }^{6}$ Memelilerde doğurganlık ve fizyolojik yaş ters orantılıdır. ${ }^{7}$ Yaş ile ilişkili üremede gerçekleşen gerileme çok etkenlidir ve büyük ölçüde mevcut oosit sayısındaki azalmaya bağlıdır; ancak azalmış memeli doğurganlığı aynı zamanda oosit kalitesi ve oositin gelişimsel potansiyeli ile de ilişkilidir. ${ }^{7}$ Maternal yaşın artışı ile birlikte oosit kalitesi düşmektedir. ${ }^{9}$ Düşük oosit kalitesinin potansiyel nedenleri azalmış ooplazma kalitesi, mitokondriyal bozukluklar ve mayoz anomalileridir.7 Yaş ile bağlantılı olarak oositte yer alan organellerin yapısal ve işlevsel açıdan bozulması, oosit kalitesinin azalması ile ilişkilendirilmiştir. ${ }^{10,11}$

Stres koşulları ve fizyolojik dengesizlikler protein katlanmasına neden olur ve hücresel protein dengesini (proteostazis) bozarlar. ${ }^{12,13}$ Hücre içinde yanlış katlanmış proteinlerin organize bir şekilde aktif olarak ayrılması için protein dengesini koruyucu stratejiler gereklidir. ${ }^{14}$ Çözünebilir yanlış katlanmış proteinlerin uzaklaştırılması hücredeki sitotoksik etkilerini ortadan kaldırabilir. ${ }^{15,16}$ C.elegans oositlerinde yapılan çalışmalar, oosit sitoplazmasında biriken protein agregatlarının mayoz bölünmede hatalara neden olabildiğini göstermiştir. ${ }^{17}$ Protein agregatlarının oluşumunun önlenmesi ve oluşan agregatların ortadan kaldırılabilmesi için vakuolar tip adenozin trifosfataz (V-ATPaz) proton pompalarının sağlayacağı asiditeye ihtiyaç duyulmaktadır. ${ }^{18}$ Protein kinaz C (PKC) aktivatörlerinin hormon bağımlı ya da hormon bağımsız yolaklar aracılığı ile V-ATPaz proton pompalarını aktive ettiği daha önce farklı hücrelerde yapılan çalışmalarda gösterilmiştir. ${ }^{19,20}$ Ayrıca fosfatidilinositol 4,5- bifosfat (PIP2)'in da V-ATPaz proton pompalarında domain etkileşimini stabilize ederek V-ATPaz pompasını aktive ettiği bilinmektedir. ${ }^{21}$

Hem fiziksel hem de etik nedenlere bağlı olarak genç ve yaşlı sağlıklı kadınlarda oosit kalitesinin karşılaştırılması güç olmaktadır. Bu nedenle oosit ile ilgili yapılan çalışmalarda hayvan modelleri kullanılması idealdir. Sığırların üreme periyodu (yaklaşık 13 yıl), rodentler de dahil olmak üzere diğer model hayvanlara göre daha uzundur ${ }^{22}$ ve insanlarınkine benzer foliküler dalgalanma, folikül seçimi, ovulasyon paterni ve yaşa bağlı hormonal değişiklik gösterirler. ${ }^{23,24}$ Ayrıca, mezbahada kesimi yapılan sı̆̆ırlardan alınan ovaryumlardan kolaylıkla oosit elde edilebilmektedir. $\mathrm{Bu}$ nedenle insanlarda üreme yaşlanması çalışmaları için, sığırların iyi bir hayvan modeli olduğu düşünülmektedir.

Çalıșmamızın amacı, V-ATPaz aktivasyonu sağlayarak 
hücresel asiditeyi artırdığı bilinen PIP2'nin, 8-13 yaş aralığındaki yaşlı sığır oositlerinin IVM kültür ortamına farklı doz ve sürelerde eklenmesinin oosit canlılığı ve olgunlaşması üzerindeki etkisinin belirlenmesidir.

\section{GEREÇ ve YÖNTEMLER}

$\mathrm{Bu}$ çalışma, mezbahada kesimi yapılan sığırlardan elde edilen ovaryumlardan toplanan oositlere deneysel araştırma yöntemleri uygulanarak laboratuvar ortamında gerçekleştirilmiştir.

\section{Sığır ovaryum eldesi}

Sığır ovaryum eldesi, İstanbul'da yer alan Narmanlar ET kombinasında veteriner hekim kontrolü altında yapılan kesimlerin hemen ardından gerçekleştirilmiştir. Yaş aralıkları 8 ile 13 arasında değişen yaşlı sığırlardan alınan ovaryumlar, 38,50C'ye 1sıtılmış fosfat tamponlu tuz (PBS) çözeltisi içeren, sıcaklığı koruyan termoslar içerisine aktarılmıştır. Bu şekilde sıcaklığı muhafaza edilen ovaryumların laboratuvara transferi yaklaşık 2 saat içerisinde sağlanmıştır.

\section{Ovaryumlardan oosit eldesi}

Oositler, sığır ovaryum foliküllerinden (Şekil-1a) 18G iğne yardımı ile aspire edilmiş, enjektöre folikül sıvısı ile birlikte çekilen kumulus-oosit kompleksleri medyum içeren cam petri kaplarına aktarılmıştır. Oosit toplama medyumu olarak, amfoterisin B $(2.5 \mathrm{mg} / \mathrm{ml})$, penisilin-streptomisin (50 mg/ml) destekli, HEPES içeren M199 medyumu kullanılmıştır. Oositler, IVM medyumu içeren damlacıklar içerisine aktarılmadan önce stereomikroskop altında kumulus hücreleri ağız pipeti yardımıyla mekanik olarak uzaklaştırılmıştır.

\section{In vitro maturasyon (IVM)}

GV aşamadaki oositler, piruvat $(0,25 \mathrm{mM})$, glukoz $(5,5$ $\mathrm{mM}$ ), penisilin/streptomisin (\%1), FCS (\%10), LH (75 $\mathrm{mIU} / \mathrm{ml})$, FSH (75 mIU/ml), östradiol ( $1 \mu \mathrm{g} / \mathrm{ml})$, ITS (\%1) destekli L-Glutamin içeren M199 medyumuna aktarılmıştır. Polistiren steril petri kapları içerisinde 38,50C'de
6 saat ve 24 saat sürelerle inkübasyon gerçekleştirilmiştir (Şekil-1b).

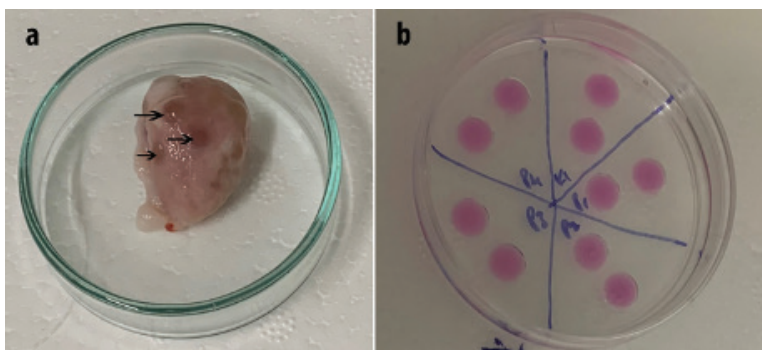

Şekil-1: a) Folikül aspirasyonu öncesi sığır ovaryumunun genel görünümü. Ok: Ovaryum folikülleri b) In vitro maturasyon (IVM) medyumu içeren polisitiren steril petri kaplarl. Kontrol: Fosfatidilinositol 4,5- bifosfat (PIP2) içermeyen medyum. P1: 0,1 $\mu$ M PIP2 içerir. P2: 0,5 $\mu$ M PIP2 içerir. P3: $1 \mu M$ PIP2 içerir. P4: $5 \mu M$ PIP2 içerir.

\section{IVM sürecinde PIP2 uygulaması}

V-ATPaz aktivasyonu sağlayarak hücresel asiditeyi artırdı$\breve{g}_{1}$ bilinen PIP2, sı ̆̆ır oositlerine uygulanan IVM medyumu içerisine $0,1 \mu \mathrm{M}(\mathrm{P} 1), 0,5 \mu \mathrm{M}(\mathrm{P} 2), 1 \mu \mathrm{M}$ (P3) ve $5 \mu \mathrm{M}(\mathrm{P} 4)$ konsantrasyonlarda eklenmiştir. Kontrol grubunda $(\mathrm{K})$ yer alan oositlerin IVM medyumuna PIP2 eklemesi yapılmamıştır. IVM sürecinin 6. ve 24. saatlerinde tüm gruplara ait oositler invert mikroskop altında gözlemlenmiş, olgunlaşmamış (polar cisimcik atılımı gerçekleşmeyen ve MII aşamasından önceki aşamalarda bulunan), olgunlaşmış (polar cisimcik atılımını tamamlamış ve MII aşamasında bulunan) ve canlılığını koruyamayan oosit sayıları belirlenmiştir. Bu deneyler, mezbahadan 3 farklı günde alınan örnekler ile $3 \mathrm{kez}$ tekrar edilmiştir. 3 farklı deneyden elde edilen oosit sayıları tüm gruplar için ayrı ayrı toplanarak elde edilen toplam oosit sayıları Tablo- 1'de belirtilmiştir. Her bir grupta yer alan (K, P1, P2, P3 ve P4) canl1 - olgunlaşmamış, canlı - olgunlaşmış ve ölü oosit yüzdeleri belirlenmiştir (Tablo -1).

\section{İstatistiksel analiz}

$\mathrm{K}, \mathrm{P} 1, \mathrm{P} 2, \mathrm{P} 3$ ve P4 gruplarında yer alan canlı - olgunlaşmamış, canlı - olgunlaşmış ve ölü oosit yüzdelerinin belirlenmesiyle elde edilen veriler Sigma Stat programı (Sigma 
Stat for Windows, version 3.0, Jandel Scientific Corp., San Rafael, CA, USA) ile istatistiksel açıdan değerlendirilmiştir. Veriler "One-way ANOVA" Holm Sidak testi ile değerlendirilmiş, biyomedikal araştırmalarda çoklu karşılaştırma prosedürleri içerisinde yalın, güvenli ve güçlü bir yöntem olarak tanımlanması nedeniyle bu test tercih edilmiştir. ${ }^{25}$ Uygulanan bu test ile canl - olgunlaşmamış, canlı - olgunlaşmış ve ölü oosit oranları açısından tüm gruplar (K, P1, P2, P3 ve P4) birbirleri ile karşılaştırılmış ve istatis- tiksel anlamlılık $\mathrm{p}<0,001$ olarak tanımlanmıştır. 6 saatlik IVM sonucu elde edilen canlı - olgunlaşmamış (Tablo-2), canlı - olgunlaşmış (Tablo-3) ve ölü (Tablo-4) oositlerin farklı gruplardaki oranlarının birbirleri ile karşılaştırılması ile elde edilen $p$ değerleri ilgili tablolarda belirtilmiştir. Aynı şekilde 24 saatlik IVM sonucu elde edilen canlı - olgunlaşmamış (Tablo-5), canlı - olgunlaşmı̧s (Tablo-6) ve ölü (Tablo-7) oositlerin farklı gruplardaki oranlarının birbirleri ile karşılaştırılması ile elde edilen p değerleri de

Tablo-1: 6 saat ve 24 saatlik IVM sürecinin ardından kontrol (PIP2 içermeyen grup), P1 (0,1 $\mu$ M PIP2), P2 (0,5 $\mu$ M PIP2), P3 (1 $\mu$ M

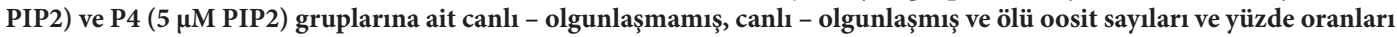

\begin{tabular}{|c|c|c|c|c|c|c|}
\hline & \multicolumn{2}{|c|}{ Canlı - olgunlaşmamış oositler } & \multicolumn{2}{|c|}{ Canlı - olgunlaşmış oositler } & \multicolumn{2}{|c|}{ Ölü oositler } \\
\hline & Sayı & Yüzde & Sayı & Yüzde & Sayı & Yüzde \\
\hline Kontrol (6 saat) & 19 & 48,71 & 0 & 0 & 20 & 51,28 \\
\hline Kontrol (24 saat) & 5 & 12,82 & 1 & 2,56 & 33 & 84,61 \\
\hline P1 (6 saat) & 11 & 35,48 & 2 & 6,45 & 18 & 58,06 \\
\hline P1 (24 saat) & 8 & 25,80 & 3 & 9,67 & 20 & 64,51 \\
\hline P2 (6 saat) & 14 & 28,00 & 1 & 2,00 & 35 & 70,00 \\
\hline P2 (24 saat) & 9 & 18,00 & 1 & 2,00 & 40 & 80,00 \\
\hline P3 (6 saat) & 16 & 36,36 & 0 & 0 & 28 & 63,63 \\
\hline P3 (24 saat) & 8 & 18,18 & 0 & 0 & 36 & 81,81 \\
\hline P4 (6 saat) & 2 & 4,16 & 0 & 0 & 46 & 95,83 \\
\hline P4 (24 saat) & 0 & 0 & 0 & 0 & 48 & 100 \\
\hline
\end{tabular}

Tablo- 2: 6 saatlik IVM sürecinin ardından kontrol (PIP2 içermeyen grup), P1 (0,1 $\mu$ M PIP2), P2 (0,5 $\mu$ M PIP2), P3 (1 $\mu$ M PIP2) ve P4 (5 $\mu$ M PIP2) gruplarında yer alan canlı - olgunlaşmamış oosit yüzdelerinin “One-Way ANOVA” Holm Sidak yöntemi ile karşılaştırılması ile elde edilen $p$ değerleri

\begin{tabular}{|l|c|c|c|c|c|c|}
\hline & $\begin{array}{c}\text { Kontrol } \\
\text { (6 saat) }\end{array}$ & P1 (6 saat) & P2 (6 saat) & P3 (6 saat) & P4 (6 saat) & Ortalama \\
Kontrol (6 saat) & --- & $\mathrm{p}=0,183$ & $\mathrm{p}=0,161$ & $\mathrm{p}=0,009$ & $\mathrm{p}<0,001$ & 48,710 \\
\hline P1 (6 saat) & $\mathrm{p}=0,183$ & --- & $\mathrm{p}=0,942$ & $\mathrm{p}=0,183$ & $\mathrm{p}<0,001$ & 35,480 \\
\hline P2 (6 saat) & $\mathrm{p}=0,161$ & $\mathrm{p}=0,942$ & --- & $\mathrm{p}=0,207$ & $\mathrm{p}<0,001$ & 28,000 \\
\hline P3 (6 saat) & $\mathrm{p}=0,009$ & $\mathrm{p}=0,183$ & $\mathrm{p}=0,207$ & --- & $\mathrm{p}<0,001$ & 36,360 \\
\hline P4 (6 saat) & $\mathrm{p}<0,001$ & $\mathrm{p}<0,001$ & $\mathrm{p}<0,001$ & $\mathrm{p}<0,001$ & 4,523 \\
\hline
\end{tabular}

Tablo- 3: 6 saatlik IVM sürecinin ardından kontrol (PIP2 içermeyen grup), P1 (0,1 $\mu$ M PIP2), P2 (0,5 $\mu$ M PIP2), P3 (1 $\mu$ M PIP2) ve P4 (5 MM PIP2) gruplarında yer alan canlı - olgunlaşmış oosit yüzdelerinin “One-Way ANOVA” Holm Sidak yöntemi ile karşılaştırılması ile elde edilen $\mathbf{p}$ değerleri

\begin{tabular}{|l|c|c|c|c|c|c|}
\hline & $\begin{array}{c}\text { Kontrol } \\
\text { (6 saat) }\end{array}$ & P1 (6 saat) & P2 (6 saat) & P3 (6 saat) & P4 (6 saat) & Ortalama \\
Kontrol (6 saat) & --- & $\mathrm{p}<0,001$ & $\mathrm{p}=0,056$ & $\mathrm{p}=1,000$ & $\mathrm{p}=1,000$ & 0,000 \\
\hline P1 (6 saat) & $\mathrm{p}<0,001$ & --- & $\mathrm{p}<0,001$ & $\mathrm{p}<0,001$ & $\mathrm{p}<0,001$ & 6,450 \\
\hline P2 (6 saat) & $\mathrm{p}=0,056$ & $\mathrm{p}<0,001$ & --- & $\mathrm{p}=0,056$ & $\mathrm{p}=0,056$ & 2,000 \\
\hline P3 (6 saat) & $\mathrm{p}=1,000$ & $\mathrm{p}<0,001$ & $\mathrm{p}=0,056$ & --- & $\mathrm{p}=1,000$ & 0,000 \\
\hline P4 (6 saat) & $\mathrm{p}=1,000$ & $\mathrm{p}<0,001$ & $\mathrm{p}=0,056$ & $\mathrm{p}=1,000$ & 0,000 \\
\hline
\end{tabular}


Tablo- 4: 6 saatlik IVM sürecinin ardından kontrol (PIP2 içermeyen grup), P1 (0,1 $\mu$ M PIP2), P2 (0,5 $\mu$ M PIP2), P3 (1 $\mu$ M PIP2) ve P4 (5 $\mathrm{MM}$ PIP2) gruplarında yer alan ölü oosit yüzdelerinin “One-Way ANOVA” Holm Sidak yöntemi ile karşılaştırılması ile elde edilen p değerleri

\begin{tabular}{|l|c|c|c|c|c|c|}
\hline & $\begin{array}{c}\text { Kontrol } \\
\text { (6 saat) }\end{array}$ & P1 (6 saat) & P2 (6 saat) & P3 (6 saat) & P4 (6 saat) & Ortalama \\
Sapma
\end{tabular}

Tablo- 5: 24 saatlik IVM sürecinin ardından kontrol (PIP2 içermeyen grup), P1 (0,1 $\mu$ M PIP2), P2 (0,5 $\mu$ M PIP2), P3 (1 $\mu$ M PIP2) ve P4 (5 $\mu$ M PIP2) gruplarında yer alan canlı - olgunlaşmamış oosit yüzdelerinin “One-Way ANOVA” Holm Sidak yöntemi ile karşılaştırılması ile elde edilen p değerleri

\begin{tabular}{|l|c|c|c|c|c|c|}
\hline & $\begin{array}{c}\text { Kontrol (24 } \\
\text { saat) }\end{array}$ & P1 (24 saat) & P2 (24 saat) & P3 (24 saat) & P4 (24 saat) & Ortalama \\
Sapma
\end{tabular}

Tablo- 6: 24 saatlik IVM sürecinin ardından kontrol (PIP2 içermeyen grup), P1 (0,1 $\mu$ M PIP2), P2 (0,5 $\mu$ M PIP2), P3 (1 $\mu$ M PIP2) ve P4 (5 4 M PIP2) gruplarında yer alan canlı - olgunlașmıș oosit yüzdelerinin “One-Way ANOVA” Holm Sidak yöntemi ile karşılaștırılması ile elde edilen $p$ değerleri

\begin{tabular}{|l|c|c|c|c|c|c|}
\hline & $\begin{array}{c}\text { Kontrol (24 } \\
\text { saat) }\end{array}$ & P1 (24 saat) & P2 (24 saat) & P3 (24 saat) & P4 (24 saat) & Ortalama \\
Sapma
\end{tabular}

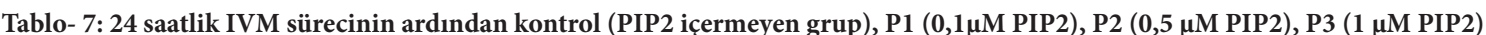
ve P4 (5 $\mu$ M PIP2) gruplarında yer alan ölü oosit yüzdelerinin “One-Way ANOVA” Holm Sidak yöntemi ile karşılaştırılması ile elde edilen $p$ değerleri

\begin{tabular}{|l|c|c|c|c|c|c|}
\hline & $\begin{array}{c}\text { Kontrol (24 } \\
\text { saat) }\end{array}$ & P1 (24 saat) & P2 (24 saat) & P3 (24 saat) & P4 (24 saat) & Ortalama \\
\hline Kontrol (24 saat) & --- & $\mathrm{p}<0,001$ & $\mathrm{p}=0,013$ & $\mathrm{p}=0,962$ & $\mathrm{p}=0,127$ & 84,610 \\
\hline P1 (24 saat) & $\mathrm{p}<0,001$ & --- & $\mathrm{p}=0,350$ & $\mathrm{p}<0,001$ & $\mathrm{p}<0,001$ & 64,510 \\
\hline P2 (24 saat) & $\mathrm{p}=0,013$ & $\mathrm{p}=0,350$ & --- & $\mathrm{p}=0,014$ & $\mathrm{p}<0,001$ & 80,000 \\
\hline P3 (24 saat) & $\mathrm{p}=0,962$ & $\mathrm{p}<0,001$ & $\mathrm{p}=0,014$ & --- & $\mathrm{p}=0,116$ & 81,810 \\
\hline P4 (24 saat) & $\mathrm{p}=0,127$ & $\mathrm{p}<0,001$ & $\mathrm{p}<0,001$ & $\mathrm{p}=0,116$ & 4,975 \\
\hline
\end{tabular}


ilgili tablolarda belirtilmiştir.

\section{BULGULAR}

6 saatlik IVM sonucunda PIP2'nin farklı konsantrasyonlarının oosit canlılığı ve olgunlaşma oranlarına etkisi IVM'in 6. saati sonunda hiçbir grupta yer alan oositlerde partenogenetik aktivasyon gözlemlenmemiştir. Invert mikroskop altında incelenen oositlerden (Şekil-2), canlılığını koruyan ancak I. mayoz bölünmeyi tamamlayarak polar cisimcik atılımı gözlemlenmeyen, olgunlaşmamış oosit oranlar1 kontrol grubunda \%48,71 $(\mathrm{n}=19), \mathrm{P} 1$ grubunda \%35,48 ( $\mathrm{n}=11)$, P2 grubunda \%28,00 ( $\mathrm{n}=14)$, P3 grubunda \%36,36 ( $\mathrm{n}=16)$ ve $\mathrm{P} 4$ grubunda \%4,16 $(\mathrm{n}=2)$ olarak belirlenmiştir. Canlılığını koruyan ve 1 . mayoz bölünmeyi tamamlayarak polar cisimcik atılımı gözlemlenen, MII aşamaya gelen olgun oositler, IVM'in 6. saatinin sonunda sadece P1 ve P2 gruplarında gözlemlenmiş ve olgunlaşma oranları sırasıyla \%6,45 $(n=2)$ ve \%2,00 $(n=1)$ olmuştur. P3 ve P4 gruplarında ise olgunlaşmış oosite rastlanmamıştır. Canlılığını koruyamayan oosit oranları ise kontrol grubunda $\% 51,28(n=20), P 1$ grubunda $\% 58,06(n=18), P 2$ grubunda $\% 70,00(n=35), P 3$ grubunda $\% 63,63(n=28)$ ve P4 grubunda \%95,83 (n=46)'tür. (Şekil-3).

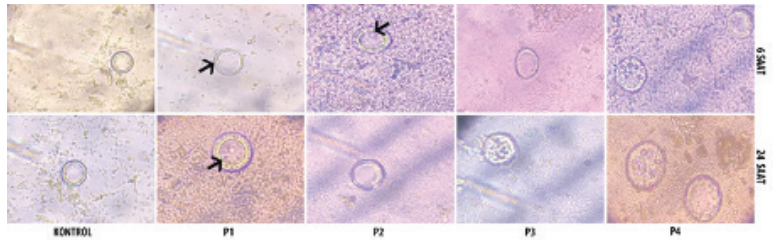

Şekil-2: In vitro maturasyon (IVM) medyumunda 6 ve 24 saat süreyle farklı konsantrasyonlarda PIP2 varliğında kültüre edilen oositlerin invert mikroskop görüntüleri. Ok: polar cisimcik. P1:0,1 $\mu M, P 2: 0,5 \mu M$ P3:1 $\mu M$ P4:5 $M$ M Fosfatidilinositol 4,5-bifosfat (PIP2) içermektedir.

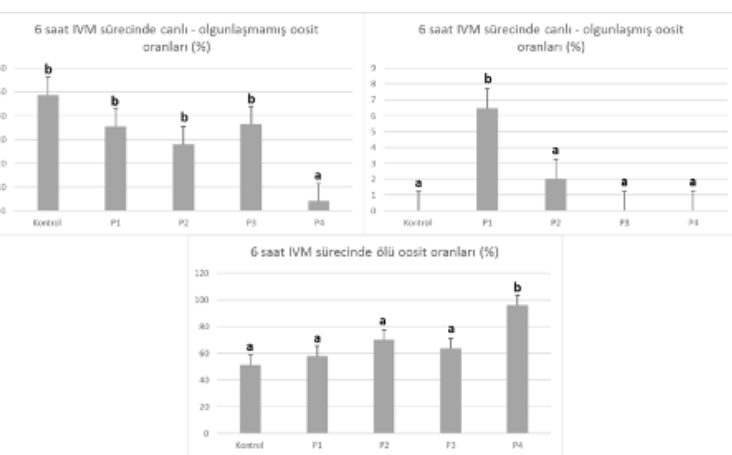

Şekil-3: In vitro maturasyon (IVM) uygulanan oositlerden 6 saat sonunda canlılı̆̆ını koruyan ancak 1. mayoz bölünmesini tamamlayarak, polar cisimcik oluşumu gözlemlenmeyen, olgunlaşmasımı tamamlamamış (canlı- olgunlaşmamış), 1. mayoz bölünmeyi tamamlayarak polar cisimcik atılımı görülen olgun (canlı - olgunlaşmış) ve ölü oosit oranlarını (\%) gösteren grafikler. Farklı harfler istatistiksel anlamlılığ ifade etmektedir $(P<0,001)$ (One way anova, Holm Sidak yöntemi). P1:0,1 $\mu M$, P2:0,5 $\mu M$ P3:1 $\mu M$ P4:5 $\mu M$ Fosfatidilinositol 4,5- bifosfat (PIP2) içermektedir.

6 saatlik IVM süreci sonunda en yüksek olgunlaşma oranının 0,1 $\mu$ M PIP2 uygulanan P1 grubunda olduğu görülmüştür ve bu oran tüm diğer gruplar ile karşılaştırıld1ğında istatistiksel olarak anlamlıdır ( $<<0,001)$ (Tablo- 3). Canlılığını koruyamayan oositlerin oranının en yüksek olduğu grup ise $5 \mu \mathrm{M}$ PIP2 uygulanan P4 grubu olarak belirlenmiş, canlı oositlerin oranlarının da bu grupta diğer gruplara göre anlamlı şekilde düşük olduğu görülmüştür $(\mathrm{p}<0,001)($ Tablo-2 ve 4).

24 saatlik IVM sonucunda PIP2'nin farklı konsantrasyonlarının oosit canlılığı ve olgunlaşma oranlarına etkisi IVM'in 24. saati sonunda da hiçbir grupta partenogenetik aktivasyona uğrayan oosite rastlanmamıştır. Invert mikroskop altında incelenen oositlerden (Şekil-2), canlılı̆̆ ${ }^{-}$ nı koruyan ancak olgunlaşmamış oosit oranları kontrol grubunda \%12,82 (n=5), P1 grubunda \%25,80 ( $\mathrm{n}=8), \mathrm{P} 2$ grubunda \%18,00 (n=9) ve P3 grubunda \%18,18 (n=8) olarak belirlenmiş, P4 grubunda 24 saatlik IVM sonunda canlı oosit gözlemlenmemiştir. Kültür süreci sonunda can- 
lılığını koruyan ve olgunlaşmış oositler kontrol, P1 ve P2 gruplarında gözlemlenmiş ve olgunlaşma oranları sırasıyla \%2,56 (n=1), \%9,67 (n=3) ve \%2,00 (n=1) olmuştur. P3 ve P4 gruplarında 24 saatlik IVM sürecinin sonunda da olgunlaşmış oosit gözlemlenmemiştir. En yüksek olgunlaşma oranı 24 saatlik IVM sonucunda da P1 grubunda elde edilmiştir ve bu oran tüm diğer gruplar ile karşılaştırıldığında istatistiksel olarak anlamlıdır $(\mathrm{p}<0,001)$ (Tablo-6). Canlılığını koruyamayan oosit oranları ise kontrol grubunda \%84,61 ( $n=33), P 1$ grubunda $\% 64,51(n=20), P 2$ grubunda \%80,00 ( $n=40)$, P3 grubunda \%81,81 $(n=36)$ ve P4 grubunda \%100 (n=48)'dür (Şekil-4). Canlılığını koruyamayan oosit oranının P1 grubunda en az olduğu, P1 grubundaki ölü oosit oranlarının kontrol, P3 ve P4 gruplarına göre istatistiksel olarak anlamlı derecede düşük olduğu görülmüştür $(\mathrm{p}<0,001)$ (Tablo-7).

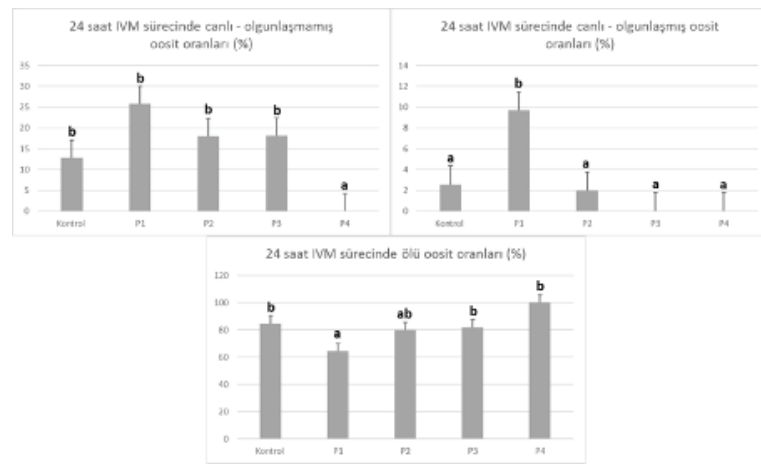

Şekil-4: In vitro maturasyon (IVM) uygulanan oositlerden 24 saat sonunda canlılı̆̆ın koruyan ancak 1. mayoz bölünmesini tamamlayarak, polar cisimcik oluşumu gözlemlenmeyen, olgunlaşmasını tamamlamamış (canlı- olgunlaşmamış), 1. mayoz bölünmeyi tamamlayarak polar cisimcik atılımı görülen olgun (canlı - olgunlaşmış) ve ölü oosit oranların (\%) gösteren grafikler. Farklı harfler istatistiksel anlamlılığ ifade etmektedir $(P<0,001)$ (One way anova, Holm Sidak yöntemi). P1:0,1 $\mu M$, P2:0,5 $\mu M$ P3:1 $\mu M$ P4:5 $\mu$ M Fosfatidilinositol 4,5- bifosfat (PIP2) içermektedir.

\section{TARTIŞMA}

Kadınlara özgü üreme yaşlanması sorunları uzun süren oogenez sürecinden kaynaklanmaktadır: Primordial oositler fetal dönemde oluşurlar ancak ovulasyon sırasında döllenebilir oositlere olgunlaşırlar. ${ }^{26}$ YÜT uygulamaları kapsamında döllenme yeterliliği olan, olgun insan oositi elde edebilmek üzere uzun süreli oosit dondurma ve oosit bağışı yöntemleri kullanılabilmektedir. ${ }^{27}$ Ancak hem oosit dondurma hem de oosit bağışının kendilerine ait teknik ve etik güçlükleri bulunmaktadır ve buna ek olarak her iki yöntemin de uygulanmaları konusunda kısıtlılıklar vardır. Bu nedenle GV aşamadaki oositlerin uygun gelişimsel yeterliliklerini ve potansiyellerini kaybetmeden IVM yöntemi ile MII aşamaya kadar olgunlaştırılabildiği kültür sistemlerinin geliştirilebilmesi oldukça önemlidir. Uygulanan IVM sistemi, oositin 1. mayoz bölünmeyi gerçekleştirmesine olanak sağlayan nuklear olgunlaşmasını ve sitoplazmik farklanmasını destekleme özelliğine sahip olmalıdır, ${ }^{28}$ böylece döllenme ve embriyonik gelișimin başarıyla gerçekleşmesi sağlanabilir. Oositlerde yaşa bağlı olarak gerçekleşen sitoplazmik bileşenlerdeki değişiklikler, oositin nuklear olgunlaşmasına engel oluşturabilmektedir. Sığırda daha önce yapılan çalışmalarda, yaşlı sığırların folikül sayılarının ve ovaryumların hormon yanıtının daha düşük olduğu belirlenmiştir. ${ }^{29}$ Yaşlı sığırlardan alınan oositlerde reaktif oksijen türleri (ROS) seviyelerinin yüksek olduğu ve mitokondriyal DNA (MtDNA) kopya sayısı ve gelişim yeteneğinin azaldığ görülmüştür..$^{30,31}$ Mitokondriyal fonksiyon bozukluğunun genç sığır oositlerinde mitokondriyal biyogenezi aktive ettiği ancak yaşlı sığır oositlerinde bu esnekliğin kaybolduğu ortaya konmuştur. ${ }^{32}$ Yaşlı sığırlardan elde edilen oositlerin nuklear olgunlaşmayı tamamlama ve döllenme yeteneğinin düşük olduğu belirlenmiştir.33 Ayrıca genç ve yaşlı sığır oositlerindeki gen ifade farklılıklarının oksidatif fosforilasyon ve mitokondriyal fonksiyon bozukluğunu ile ilişkili olduğu gösterilmiştir. ${ }^{33}$ Gerçekleştirilen bu çalışmada PIP2, yaşlı sığır oositlerine IVM sürecinde farklı dozlarda ve sürelerde uygulanmış ve özellikle $0,1 \mu \mathrm{M}$ konsantrasyonda uygulandığında oosit olgunlaşma oranlarının daha yüksek konsantrasyonlar 
içeren gruplara ve PIP2'nin uygulanmadığg kontrol grubuna göre daha fazla olduğu görülmüştür. Farklı hücrelerde hücresel asiditeyi artırarak, protein agregatlarını ortadan kaldırdığı bilinen PIP2'nin,, ${ }^{20,21}$ mevcut çalışmadaki oosit olgunlaşmasını artırdığının belirlenmesi, bu molekülün oositlerde de sitoplazmik kompozisyon açısından benzer bir etki yarattığını düşündürmektedir. PIP2'nin belirli fosfolipaz C izoformları tarafından katalize edilen hidrolizi sonucunda diaçilgliserol (DAG) ve inositol-3 fosfat (IP3) oluşumu gerçekleşmektedir. ${ }^{34} \mathrm{Bu}$ hidroliz ürünlerinden DAG doğrudan protein kinaz C (PKC) aktivasyonuna neden olmaktadir. ${ }^{35}$ IP3 ise endoplazmik retikulum membranında yer alan $\mathrm{Ca}+2$ kanallarının açılmasını sağlamakta ve Ca+2 artışı ile PKC aktivasyonunu gerçekleştirmektedir.36 Dolayısıyla PIP2’nin varlığı DAG ve IP3 aracılığıyla PKC aktivasyonu ile ilişkilidir. PKC’nin aktivasyonunun ise sığır oosit maturasyonu sürecinde nuklear maturasyonu artırıcı yönde etki yaptığı daha önceki çalışmalarda belirlenmiştir. ${ }^{37}$ Fare ovaryumunda daha önce gerçekleştirdiğimiz çalışmalarda belirli PKC izotiplerinin (PKCE) özellikle oositlerde yerleşim gösterdiği belirlenmiş, ${ }^{38} \mathrm{bu}$ nedenle PKC'nin belirli izotiplerinin memeli oosit maturasyonu üzerinde etkili olabileceği düşünülmüştür. Ayrıca fare ovaryum folikül kültürü modelinde, konvensiyonel PKC izotiplerinden PKCa ve PKC $\beta I$ 'in FSH ile indüklenen fare oosit maturasyonunun tamamlanmasında EGFR aktivasyonu gerçekleştirerek etkili olduğu belirlenmiştir. ${ }^{39}$ Önceki yıllarda gerçekleştirdiğimiz sığır ovaryum folikül kültürü modelinde de PKC ile etkileşimi olduğu bilinen Akt ve mitojen ile aktive olan protein kinazların (MAPK) foliküler aktivasyon ile de ilişkili olabileceği belirlenmiştir. ${ }^{40}$ Dolayısıyla, mevcut çalışmada PIP2'nin sığır oosit maturasyonu üzerindeki etkisinin, oosit maturasyonunda rol oynadığı düşünülen PKC sinyalinin ve ilişkili yolakların aktivasyonuna katkı sağlayarak gerçekleşmiş olabileceği düşünülmektedir.

Oosit olgunlaşması sırasında mayoz bölünmenin devaml1lığı için gerekli olan siklin bağımlı kinaz-1(CDK1) - siklin B kompleksinin olgunlaşmamış deniz yıldızı oositlerinde agregatlar halinde bulunduğu ve olgunlaşma sırasında bu kompleks aktif hale geldiği anda agregatın dağıldığı belirlenmiştir. ${ }^{41}$ Protein agregatlarının oluşumunun önlenmesi ve oluşan agregatların ortadan kaldırılarak oosit sitoplazmasının protein dengesinin korunmasının lizozomlara bağlı olduğu ve lizozomların asiditesinin korunmasının lizozomun bu dengeyi sağlama konusundaki etkinliğini artırdığ́ gösterilmiştir. ${ }^{17}$ Lizozomlarda, düşük pH seviyelerinde ( $\mathrm{pH} 4.5-5.5$ ) optimum aktivite gösteren proteazlar bulunur. ${ }^{18}$ Lizozomlardaki bu düşük $\mathrm{pH}$ düzeyi membrana bağlı proton pompaları ile sağlanmaktadır. ${ }^{42}$ Lizozom asiditesinin sağlanması için proton pompalarının aktive edilmesi gerekmektedir. Progesteron ile aktive edilen X. laevis oositlerinin çok sayıda asidik lizozoma sahip olduğu gösterilmiştir. ${ }^{17} \mathrm{Bu}$ mekanizmanın memeli türlerinde de korunmuş olabileceği düşünülmektedir. Lizozom asiditesi, lizozom membranında yer alan V-ATPaz proton pompalarının aktivasyonu ile sağlanabilmektedir. ${ }^{21}$ ATP hidrolizi ile proton pompasında yer alan proteolipid c-halkasının dönmesi sonucu proton hareketi gerçekleşmekte ve $\mathrm{H}+$ konsantrasyonu bu şekilde düzenlenmektedir. ${ }^{20}$ Mevcut çalışmada proton pompası aktivasyonu gerçekleştirdiği bilinen PIP2'nin oosit olgunlaşması üzerindeki olumlu etkisi, PIP2'nin oositlerde lizozomal aktivasyon aracılığ 1 ile oositlerin protein dengesi üzerinde etkili olabileceğini göstermektedir. Yaşlı oositlerde özellikle artış gösterdiğini düşünülen protein agregatlarının ${ }^{43}$ ortadan kaldırılması için lizozomların asiditesinin proton pompası aktivatörleri aracılığıyla yüksek düzeye ulaştırılması, bu oositlerdeki olgunlaşma oranının artırılması için önem taşımaktadır.

IVM işleminin uygun sürelerde gerçekleşmesi oositin en uygun şekilde olgunlaşmasını etkilediği kadar, IVM ile elde edilen oositlerden gelişen embriyoların gelişim sürecine de etki etmektedir. Birinci polar cisimcik atılım oranı IVM'in daha erken saatlerinde gerçekleşirken, en iyi embriyo gelişiminin 18 saat süresince IVM uygulanan oositler ile gerçekleştiği belirlenmiştir. ${ }^{44}$ IVM'in uygun olmayan sürelerde gerçekleştirilmesi anormal kromatin oluşumu, oosit yaşlanması ve gelişimsel yeterliliğinin ortadan 
kalkmasına neden olabilmektedir. ${ }^{44}$ Memeli oositlerinin ovulasyon sonrası yaşlanmasının da hem in vivo hem in vitro koşullarda mayoz bölünmenin metafaz evresinde duraklamanın gerçekleşmemesine, anormal iğ gelişimi, kromozomların yanlış yerleşim göstermesine, organellerin bozulmasına ve gelişimsel yeterliliğin kaybolmasına neden olan diğer hücresel bozukluklara yol açtığ belirlenmiştir. $^{45}$ IVM süresinin kısaltılmasının, uzun süreler uygulanan IVM'e göre oositlerin gelişimsel yeterliliğini anlamlı derecede artırdığı belirlenmiştir. ${ }^{46}$ Mevcut çalışmada 6 saat süreli kısa IVM protokolünde 24 saat süreli uzun IVM protokolüne göre oosit olgunlaşma oranları daha düşük olmakla birlikte, canlılığını koruyan oositlerin oranı çok daha yüksektir. Her iki koşulda da PIP2'nin düşük konsantrasyonlarda oosit olgunlaşma oranlarını artırdığı görülmektedir. In vitro yaşlanma sırasında lizozomların hücrede belirli bölümlere ayrılmasının oosit sağlı̆̆ı açısından önemli olduğu ortaya konmuştur, ayrıca lizozom boyutlarının da ilerleyen kültür sürecinde arttığı belirlenmiştir. ${ }^{45}$ Bu çalışmadan elde edilen verilere göre de uzun kültür sürecinde PIP2'nin özellikle 0,1 $\mu \mathrm{M}$ konsantrasyonda hem oosit canlılık hem de olgunlaşma oranlarını artırmış olmasının, bu aşamada oositin lizozomal aktivasyon ihtiyacını karşılayabilmesinden kaynaklandığını düşündürmektedir.

Oositlerde nuklear olgunlaşması başarılı bir şekilde gerçekleşmiş olsa bile, gelişimsel yeterliliğin düşük düzeyde olması, oositin sitoplazmik olgunlaşmasının doğru şekilde gerçekleşmediğinin göstergesi olabilmektedir. ${ }^{46}$ Bu nedenle, sitoplazmik olgunlaşmanın sağlıklı bir şekilde gerçekleşebilmesi için IVM sistemine çeşitli antioksidanlar ve gelişim faktörleri eklenebilmektedir. ${ }^{47}$ IVM medyumuna PIP2 uygulaması yapılan bu çalışmada, PIP2'nin oositin protein dengesine etki ederek sitoplazmik olgunlaşmayı olumlu yönde etkilendiği ve buna bağlı olarak nuklear olgunlaşma oranlarında artış görülebildiği düşünülmektedir.

\section{Teșekkür}

$\mathrm{Bu}$ çalışma $118 \mathrm{~S} 772$ proje numarası ile TÜBİTAK tarafından desteklenmektedir.
Çalışmanın gerçekleşmesi sırasındaki teknik desteklerinden dolayı Narmanlar ET kombinası yetkilisi Yusuf Narman ve veteriner hekim Yılmaz Küçükafacan'a teşekkür ediyorum. 
1. Hunter RH, Cook B, Baker TG. Dissociation of response to injected gonadotropin between the Graafian follicle and oocyte in pigs. Nature 1976; 260:156-158.

2. Walls ML, Hunter T, Ryan JP, Keelan JA, Nathan E, Hart RJ. In vitro maturation as an alternative to standard in vitro fertilization for patients diagnosed with polycystic ovaries: a comparative analysis of fresh, frozen and cumulative cycle outcomes. Hum Reprod 2015; 30:88-96.

3. Edwards RG. Are minimal stimulation IVF and IVM set to replace routine IVF? Reprod Biomed Online 2007; 14:267-270

4. Smitz JE, Thompson JG, Gilchrist RB. The promise of in vitro maturation in assisted reproduction and fertility preservation. Semin Reprod Med 2011; 29:24-37.

5. Nogueira D, Sadeu JC, Montagut J. In vitro oocyte maturation: current status. Semin Reprod Med 2012; 30:199-213.

6. Wiser A, Son WY, Shalom-Paz E, Reinblatt SL, Tulandi T, Holzer H. How old is too old for in vitro maturation (IVM) treatment? Eur J Obstet Gynecol Reprod Biol 2011; 159:381-383.

7. Qiao J, Wang ZB, Feng HL, Miao YL, Wang Q, Yu Y, et al. The root of reduced fertility in aged women and possible therapentic options: current status and future perspects. Mol Aspects Med 2014; 38:54-85.

8. Faddy MJ. Follicle dynamics during ovarian ageing. Mol Cell Endocrinol 2000; 163:43-48.

9. Cheng EH, Chen SU, Lee TH, Pai YP, Huang LS, Huang CC, et al. Evaluation of telomere length in cumulus cells as a potential biomarker of oocyte and embryo quality. Hum Reprod 2013; 28:929-936

10. Kujjo LL, Acton BM, Perkins GA, Ellisman MH, D'Estaing SG, Casper RF, et al. Ceramide and its transport protein (CERT) contribute to deterioration of mitochondrial structure and function in aging oocytes. Mech Ageing Dev 2013; 134:43-52.

11. Tilly JL, Sinclair DA. Germline energetics, aging, and female infertility. Cell Metab 2013; 17:838-850.

12. Kaganovich D, Kopito R, Frydman J. Misfolded proteins partition between two distinct quality control compartments. Nature 2008; 454:1088-1095.

13. Tyedmers J, Mogk A, Bukau B. Cellular strategies for controlling protein aggregation. Nat Rev Mol Cell Biol 2010; 11:777-788.

14. Chen B, Retzlaff M, Roos T, Frydman J. Cellular strategies of protein quality control. Cold Spring Harb Perspect Biol 2011; 3:a004374.

15. Arrasate M, Mitra S, Schweitzer ES, Segal MR, Finkbeiner S. Inclusion body formation reduces levels of mutant huntingtin and the risk of neuronal death. Nature 2004; 431:805-810.

16. Wolfe KJ, Ren HY, Trepte P, Cyr DM. The Hsp70/90 cochaperone, Stil, suppresses proteotoxicity by regulating spatial quality control of amyloid-like proteins. Mol Biol Cell 2013; 24:3588-3602.

17. Bohnert KA, Kenyon C. A lysosomal switch triggers proteostasis renewal in the immortal C. elegans germ lineage. Nature 2017; 551:629-633.

18. Ohkuma S, Moriyama Y, Takano T. Identification and characterization of a proton pump on lysosomes by fluorescein-isothiocyanate-dextran fluorescence. Proc Natl Acad Sci U S A 1982; 79:2758-2762.

19. Rothenberger F, Velic A, Stehberger PA, Kovacikova J, Wagner CA. Angiotensin II stimulates vacuolar H+-ATPase activity in renal acid-secretory intercalated cells from the outer medullary collecting duct. J Am Soc Nephrol 2007; 18:2085-2093.

20. Breton S, Brown D. Regulation of luminal acidification by the V-ATPase. Physiology (Bethesda) 2013; 28:318-329.

21. Li SC, Diakov TT, Xu T, Tarsio M, Zhu W, Couoh-Cardel S, et al. The signaling lipid PI (3,5) $P(2)$ stabilizes V(1)-V(o) sector interactions and activates the V-ATPase. Mol Biol Cell 2014; 25:1251-1262.

22. Erickson BH, Reynolds RA, Murphree RL. Ovarian characteristics and reproductive performance of the aged cow. Biol Reprod 1976; 15:555-560.

23. Baerwald AR, Adams GP, Pierson RA. Characterization of ovarian follicular wave dynamics in women. Biol Reprod 2003; 69:1023-1031.

24. Adams GP, Jaiswal R, Singh J, Malhi P. Progress in understanding ovarian follicular dynamics in cattle. Theriogenology 2008; 69:72-80.

25. Ludbrook J. Multiple comparison procedures updated. Clin Exp Pharmacol Physiol 1998; 25:1032-1037.

26. Broekmans FJ, Soules MR, Fauser BC. Ovarian aging: mechanisms and clinical consequences. Endocr Rev 2009; 30:465-493.
27. Li XH, Chen SU, Zhang X, Tang M, Kui YR, Wu X, et al. Cryopreserved oocytes of infertile couples undergoing assisted reproductive technology could be an important source of oocyte donation: a clinical report of successful pregnancies. Hum Reprod 2005; 20:3390-3394.

28. Banwell KM, Thompson JG. In vitro maturation of Mammalian oocytes: outcomes and consequences. Semin Reprod Med 2008; 26:162-174.

29. Malhi PS, Adams GP, Singh J. Bovine model for the study of reproductive aging in women: follicular, luteal, and endocrine characteristics. Biol Reprod 2005; 73:45-53.

30. Iwata H, Goto H, Tanaka H, Sakaguchi Y, Kimura K, Kuwayama T, et al. Effect of maternal age on mitochondrial DNA copy number, ATP content and IVF outcome of bovine oocytes. Reprod Fertil Dev 2011; 23:424-432.

31. Takeo S, Kawahara-Miki R, Goto H, Cao F, Kimura K, Monji Y, et al. Age-associated changes in gene expression and developmental competence of bovine oocytes, and a possible countermeasure against age-associated events. Mol Reprod Dev 2013; 80:508-521.

32. Kansaku K, Takeo S, Itami N, Kin A, Shirasuna K, Kuwayama T, et al. Maternal aging affects oocyte resilience to carbonyl cyanide-m-chlorophenylhydrazone-induced mitochondrial dysfunction in cows. PLoS One 2017; 12:e0188099.

33. Yamamoto T, Iwata $H$, Goto $H$, Shiratuki S, Tanaka H, Monji Y, et al. Effect of maternal age on the developmental competence and progression of nuclear maturation in bovine oocytes. Mol Reprod Dev 2010; 77:595-604.

34. Amdani SN, Jones C, Coward K. Phospholipase C zeta (PLCzeta): oocyte activation and clinical links to male factor infertility. Adv Biol Regul 2013; 53:292-308.

35. Kolczynska K, Loza-Valdes A, Hawro I, Sumara G. Diacylglycerol-evoked activation of PKC and PKD isoforms in regulation of glucose and lipid metabolism: a review. Lipids Health Dis 2020; 19:113.

36. Davis JS, Alila HW, West LA, Corradino RA, Hansel W. Acute effects of prostaglandin F2 alpha on inositol phospholipid hydrolysis in the large and small cells of the bovine corpus luteum. Mol Cell Endocrinol 1988; 58:43-50.

37. Mondadori RG, Neves JP, Goncalves PB. Protein kinase C (PKC) role in bovine oocyte maturation and early embryo development. Anim Reprod Sci 2008; 107:20-29.

38. Tepekoy F, Ustunel I, Akkoyunlu G. Protein kinase C isoforms alpha, delta and epsilon are differentially expressed in mouse ovaries at different stages of postnatal development. J Ovarian Res 2014; 7:117.

39. Wang J, Chen $Q$, Zhou J, Wen J, Bian F, Li G, et al. Specific protein kinase C isoforms alph and betaI are involved in follicle-stimulating hormone-induced mouse follicle-enclosed oocytes meiotic resumption. PLoS One 2012; 7:e45043.

40. Tepekoy F, Akkoyunlu G. The effect of FSH and activin A on Akt and MAPK1/3 phosphorylation in cultured bovine ovarian cortical strips. J Ovarian Res 2016; 9:13.

41. Slepchenko BM, Terasaki M. Cyclin aggregation and robustness of bio-switching. Mol Biol Cell 2003; 14:4695-4706.

42. Korovila I, Hugo M, Castro JP, Weber D, Hohn A, Grune T, et al. Proteostasis, oxidative stress and aging. Redox Biol 2017; 13:550-567.

43. Wang T, Babayev E, Jiang Z, Li G, Zhang M, Esencan E, et al. Mitochondrial unfolded protein response gene Clpp is required to maintain ovarian follicular reserve during aging, for oocyte competence, and development of pre-implantation embryos. Aging Cell 2018; 17:e12784

44. Park YS, Kim SS, Kim JM, Park HD, Byun MD. The effects of duration of in vitro maturation of bovine oocytes on subsequent development, quality and transfer of embryos. Theriogenology 2005; 64:123-134.

45. Lin T, Lee JE, Kang JW, Shin HY, Lee JB, Jin DI. Endoplasmic Reticulum (ER) Stress and Unfolded Protein Response (UPR) in Mammalian Oocyte Maturation and Preimplantation Embryo Development. Int J Mol Sci 2019; 20

46. Kwak SS, Yoon JD, Cheong SA, Jeon Y, Lee E, Hyun SH. The new system of shorter porcine oocyte in vitro maturation (18 hours) using $>/=8 \mathrm{~mm}$ follicles derived from cumulus-oocyte complexes. Theriogenology 2014; 81:291-301.

47. You J, Kim J, Lim J, Lee E. Anthocyanin stimulates in vitro development of cloned pig embryos by increasing the intracellular glutathione level and inhibiting reactive oxygen species. Theriogenology 2010; 74:777-785. 